\title{
CORRECTION OF THE ATTENUATION OF THE LOW-PASS BIQUAD IN THE CURRENT MODE BASED ON PROTOTYPE IN VOLTAGE MODE
}

\author{
Bohumil BRTNÍK, David MATOUŠEK \\ Department of Electrical Engineering University of Pardubice, 53002 Pardubice, Czech Republic, \\ E-mail: bohumil.brtnik@upce.cz,david.matousek@upce.cz
}

\begin{abstract}
The second order Sallen-Key low-pass filter structures have one disadvantage in the voltage and current mode, it is a decreasing of the attenuation in the stopband. This fact is caused by losses of the amplification factor of active elements at high frequencies. Some solutions of this problem had been already published for circuits working in the voltage mode. This article presents one of the possible solutions of this problem for circuits working in the current mode.
\end{abstract}

Keywords: Circuit in current mode, circuit in voltage mode, adjoint transformation, biquad, low pass filter, Sallen-Key filter structure

\section{INTRODUCTION}

Filter characteristics in the transition area between passband and stopband frequencies are described in the generally available literature. For example, a biquad in the current mode (CM) that is shown in Fig. 1 is described in [1].

We can see that this is a Sallen-Key low pass filter structure [2], [3], [4], [5] based on a polynomial structure. An active element is a current controlled current source (CCCS). The CCCS has a current amplification factor marked as $K$.

The CCCS is composed of transistors. But this fact evokes the key problem of this way of CCCS realization, because the transistor amplification factor is decreased with increasing frequency. Therefore, the current amplification factor $K$ decreases with frequency, too.

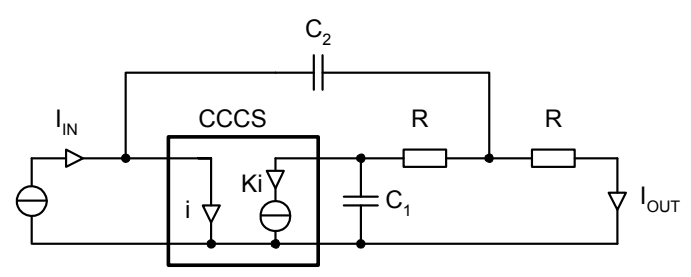

Fig. 1 Schematic diagram of biquad in the current mode

\section{FORMULATION OF THE PROBLEM}

We consider the stopband, now. We know that the amplification factor $K$ is reduced to zero at high frequencies. The output current of the biquad would be equaled to zero in this case, too.

The real CCCS structure has nonzero value of the input resistance $r$ (thus $r \neq 0$ ). Reactance of capacitors nears to zero for frequencies closely to infinite. The amplification factor $K$ nears to zero at high frequencies, too.

Thus schematic diagram of considered filter is adapted to form that is shown in Fig. 2. An input signal goes to the output terminals through passive elements only, now. The current ratio has nonzero value in this case (1)
$\frac{I_{\text {OUT }}}{I_{I N}}=\frac{r}{R+2 \cdot r}$

where: $I_{I N}-$ input current, $I_{O U T}-$ output current, $r$ - input resistance of CCCS and $R$ - resistance of working resistor in the filter.

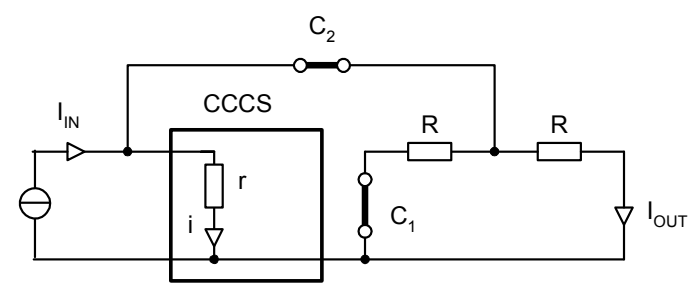

Fig. 2 Simplified equivalent circuit of biquad at high frequencies

The Eq. (1) shows fact that the current ratio of this filter does not decrease to zero at high frequencies. Thus the filter attenuation in the stopband does not increase to infinity, but it is determined by (2).

$a=-20 \cdot \log \left(\frac{r}{R+2 \cdot r}\right)$

where: $a$ - the attenuation, $r$ - input resistance of CCCS and $R$ - resistance of working resistor in the filter.

\section{PROPOSED SOLUTION}

The same problem occurs for Sallen-Key low pass biquad structure working in the voltage mode (VM).

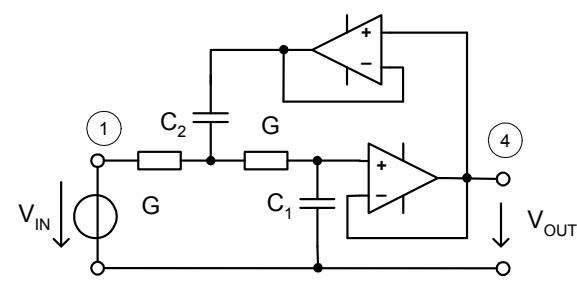

Fig. 3 Proposed solution for circuit in the voltage mode [6] 
Punčochář [6] proposes solution of this problem by following way: plugging another active element (that is an operational amplifier in VM) into the feedback loop. This proposed structure (for VM) is shown in Fig. 3.

\subsection{Adjoint transformation principle}

A generally known principle for conversion circuits working in the voltage mode to the current mode is called adjoint transformation [7] to [10]. A general principle of the adjoint transformation is illustrated by Fig. 4 .

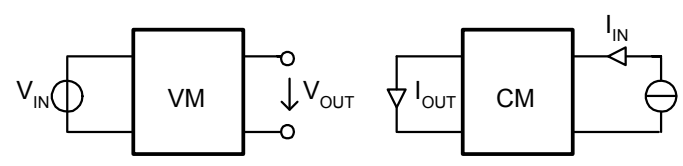

Fig. 4 The principle of the adjoint transformation

A simple resistive divider [11] is used for explanation adjoint transformation, now. We consider VM and $\mathrm{CM}$ circuits from Fig. 5, these circuits contain two resistors named $\mathrm{R}_{1}, \mathrm{R}_{2}$.

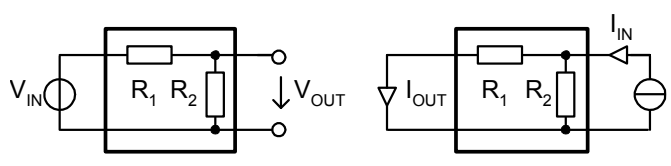

Fig. 5 Example of the adjoint transformation

The voltage divider in VM circuit is described by equation (3) and the current divider in $\mathrm{CM}$ circuit is described by equation (4).

$$
\begin{aligned}
V_{\text {OUT }}=V_{I N} \cdot \frac{R_{2}}{R_{1}+R_{2}} \\
I_{\text {OUT }}=\frac{I_{I N} \cdot \frac{R_{1} \cdot R_{2}}{R_{1}+R_{2}}}{R_{1}}=I_{I N} \cdot \frac{R_{2}}{R_{1}+R_{2}}
\end{aligned}
$$

We can see that the voltage ratio from (3) and current ratio from (4) are the same (5).

$\frac{V_{\text {OUT }}}{V_{I N}}=\frac{R_{2}}{R_{1}+R_{2}}=\frac{I_{\text {OUT }}}{I_{I N}}$

The general mathematical formulation of the adjoint transformation (see [8]) is (6).

$\frac{V_{\text {OUT }}}{V_{I N}}=\frac{I_{\text {OUT }}}{I_{I N}}$

where: $V_{I N}, V_{O U T}$ - voltages in VM circuit, $I_{I N}, I_{O U T}$ - currents in CM circuit.

\subsection{Adjoint transformation usage}

After application the adjoint transformation into the circuit from Fig. 3 we have the new circuit in form that is shown in Fig. 6.
The input signal does not cross via passive branch to the output terminals in this circuit, because this signal way is closed by new active element named $\mathrm{CCCS}_{2}$.

The element $\mathrm{CCCS}_{2}$ in final Fig. 6 is connected as a current follower (thus $I_{I N}=I_{O U T}$ ). This solution is similar to previous circuit that is shown in Fig. 3, because operational amplifier in feedback loop is connected as a voltage follower in circuit working in the voltage mode.

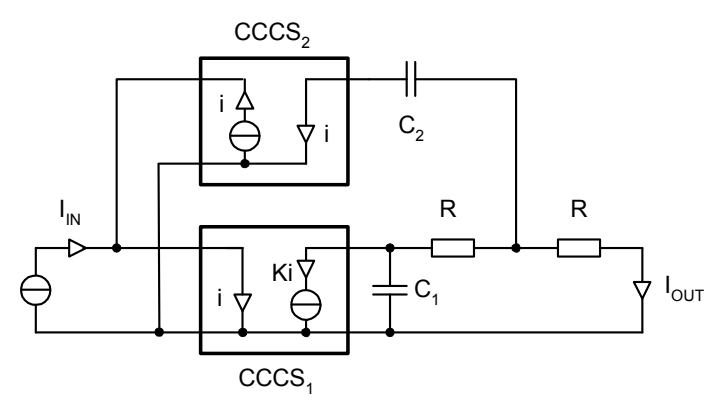

Fig. 6 Proposed circuit from Fig. 3 in the current mode

The Eq. (2) shows fact that decreasing of the input resistance $r$ evokes increasing of the attenuation $a$. This fact may be expressed for frequencies closely to infinite (7).

$\lim _{r \rightarrow 0} a(r)=-20 \cdot \lim _{r \rightarrow 0}\left\{\log \left(\frac{r}{R+2 \cdot r}\right)\right\}=+\infty$

where: $a-$ the attenuation, $r$ - input resistance of CCCS and $R$ - resistance of working resistor in the filter.

\subsection{Verification}

Toumazou [1] assumes that all circuit elements (CCCS, R, C) are ideal, but real elements have parasitic properties. Therefore, comparison of the original and the proposed circuits [12] was performed by computer simulation. The above mentioned theoretical conclusions were verified by simulations performed by SPICE-like simulators Microcap 10 and LTspiceIV.

The original circuit from Fig. 1 is redrawn in Fig. 7. Component $F_{1}$ is CCCS with the amplification factor $K=1$, but the input resistance is set to nonzero value, i.e. $r=0.1 \Omega$. If the input resistance is equal to zero, then branch with capacitor $\mathrm{C}_{2}$ is initialized by the zero voltage in the node 2 and previously described effect is not appeared.

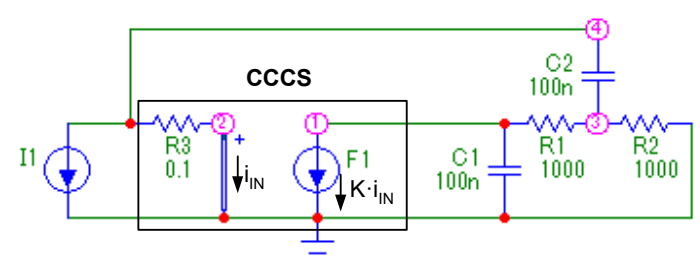

Fig. 7 Schematic diagram of original circuit drawn in Microcap 10

Similarly, the proposed circuit from Fig. 6 is redrawn in Fig. 8. 


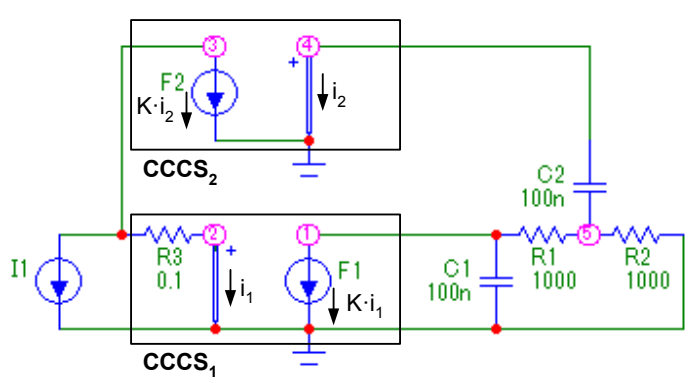

Fig. 8 Schematic diagram of proposed circuit drawn in Microcap 10

Simulated results of circuit according to Fig. 7 (see Fig. 9) show that the difference between maximal and minimal magnitude is $80 \mathrm{~dB}$, This value is corresponding to the ratio between input and output current (i.e. this value is corresponding to the ratio between input resistance $R_{3}$ of the CCCS and resistance of resistor $R_{2}$ ).

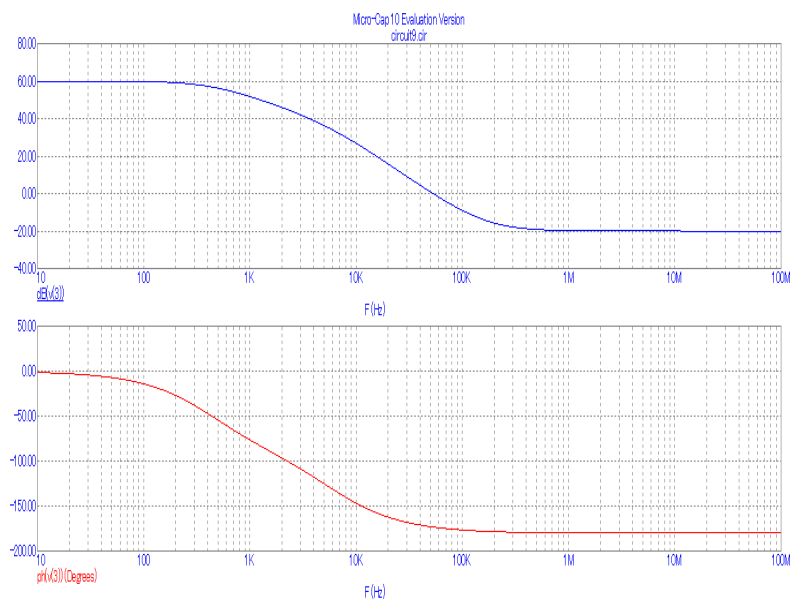

Fig. 9 Bode plot of the original circuit from Fig. 7

Simulated results of both circuits may be compared by Fig. 9 and Fig. 10. Magnitude plot from Fig. 9 matches to theoretically mentioned results, see Eq. 2. Similarly, the magnitude plot from Fig. 10 has monotonous character in the stop band. Therefore, the frequency response corresponds to Eq. 7 .

As we can see, the theoretical results are fully verified.
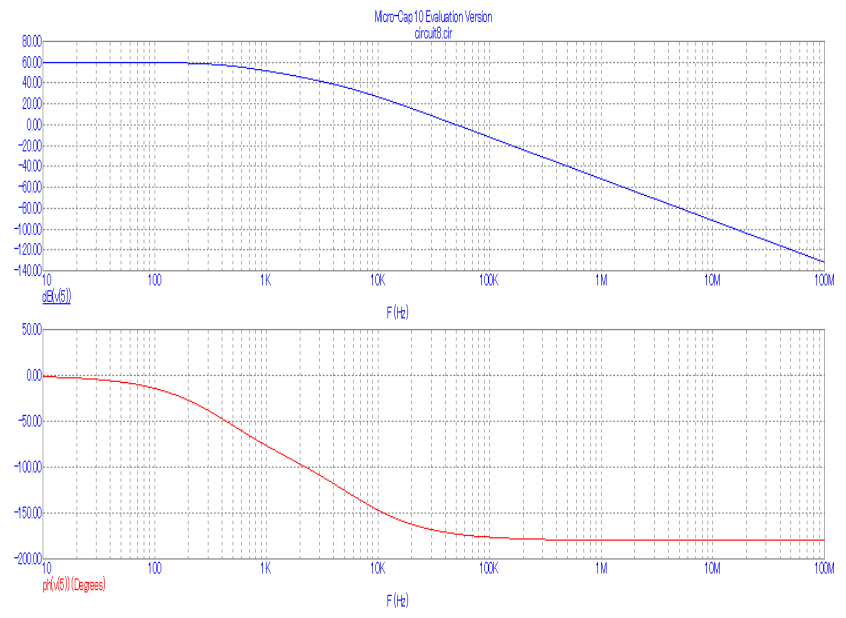

Fig. 10 Bode plot of the proposed circuit from Fig. 8
In the second step, the effect of the input resistance was explored by parametric sweep analyse. The input resistance was swept from $1 \mathrm{~m} \Omega$ to $1 \Omega$ logarithmically.

Figure 11 documents fact that the input resistance has a strong effect to usable band of the frequency response.

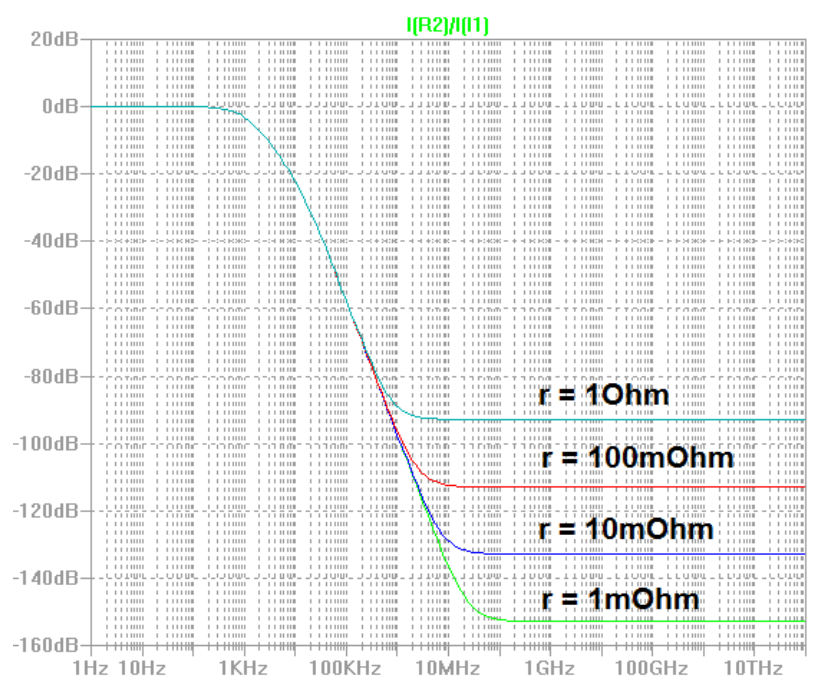

Fig. 11 Magnitude plot of the original circuit with input resistance sweeping $\left(\mathrm{C}_{1}=\mathrm{C}_{2}=1 \mathrm{nF}, \mathrm{R}_{1}=\mathrm{R}_{2}=44 \mathrm{k} \Omega\right)$

Similarly, the input resistance has effect to the frequency response of improved circuit, see Fig. 12. Declination of the magnitude plot is changed, but this characteristic is still monotonous. Thus the attenuation is not stopped.

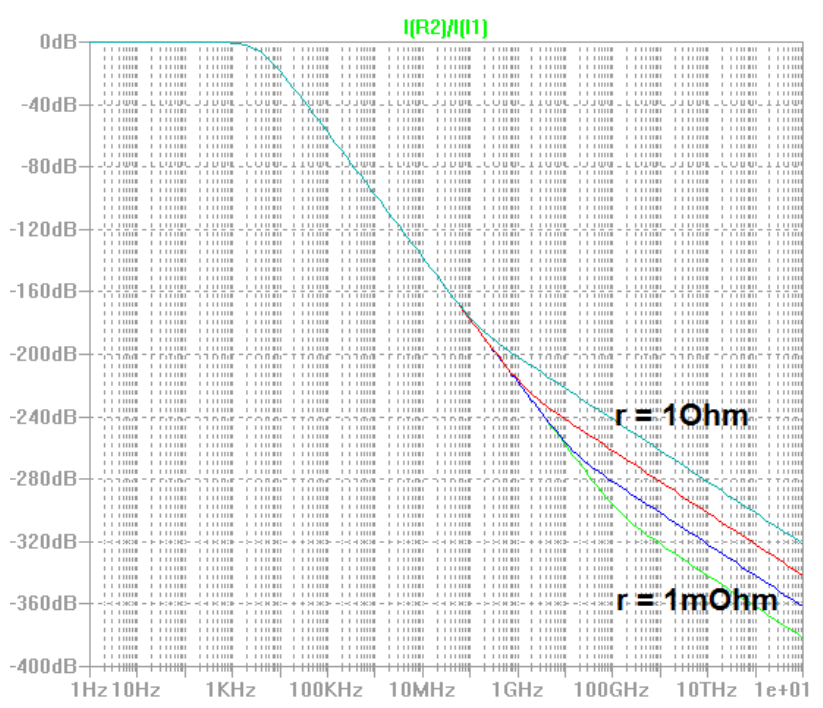

Fig. 12 Magnitude plot of the proposed circuit with input resistance sweeping $\left(\mathrm{C}_{1}=\mathrm{C}_{2}=1 \mathrm{nF}, \mathrm{R}_{1}=\mathrm{R}_{2}=44 \mathrm{k} \Omega\right)$

Finally, the proposed circuit with real components was simulated. Both CCCSs were realised by simply bipolar current mirrors. Transistors of type 2SC4102 were used for realisation of these current mirrors, because this transistor type had the smallest feedback transfer from all available transistors. Therefore, influence of the feedback transfer had negligible character, only.

Schematic diagram of proposed circuit derived from Fig. 8 is drawn in Fig. 13. Quiescent point of transistors is set by power supplies $I_{l}$ and $V_{l}$. 


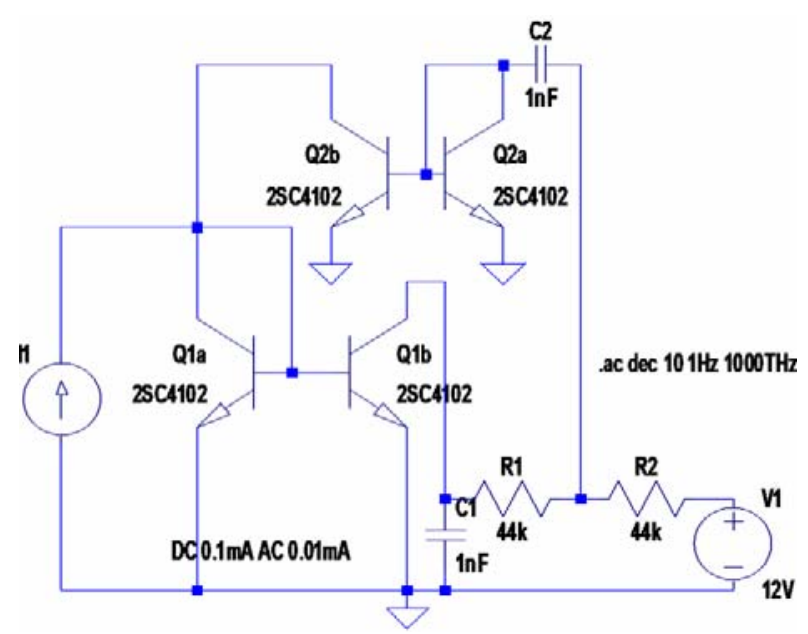

Fig. 13 Schematic diagram of biquad realised by current mirrors drawn in LTspiceIV

Result magnitude plot is drawn in Fig. 14. The magnitude declines over whole stop band. The nonzero value of the input resistance causes breakpoints in the frequency response, but this characteristic has monotonous character.

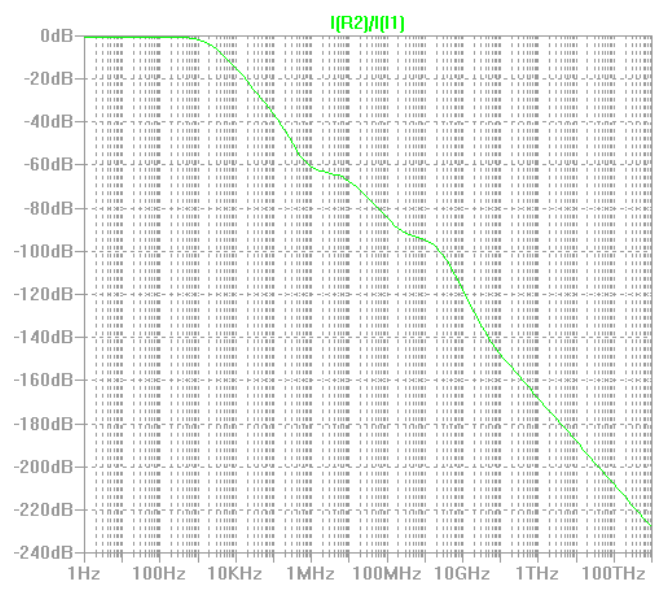

Fig. 14 Magnitude plot of the circuit from Fig. 13

\section{CONCLUSIONS}

The purpose of the article was to show the behaviour of the circuit which describes Toumazou in [1] at high frequencies. Toumazou assumes that all circuit elements (CCCS, R, C) are ideal. Presented simulation results show that the solving is usable for real transistors very well, too.

\section{ACKNOWLEDGMENTS}

The published research results were supported by the Internal Grant Agency of University of Pardubice, the project SGFEI 2016.

\section{REFERENCES}

[1] TOUMAZOU, Ch. - LIDGEY, F. J. - HAIGH, D. G.: Analogue IC design the current-mode approach, IEE Peter Peregrinus, London, pp. 446-447, April 1990.
[2] BIOLEK, D.: Solving electric circuits, BEN Publisher, Prague, pp. 85, 2004.

[3] WINDER, S.: Analogue and digital filter design, Elsevier Science, USA, pp. 133-135, 2002.

[4] THEDE, L.: Practical analog and digital filter design, Artech House, Inc., pp. 87-95, 2004.

[5] MARTINEK, P. - BOREŠ, P. - HOSPODKA, J.: Electric filters, CTU Publisher, Prague, pp. 98-101, 2003.

[6] PUNČOCHÁŘ, J.: Low-pass filter Sallen and Key with real operational amplifiers, Elektrorevue, BUT, Brno, 2005/10.

[7] TOUMAZOU, Ch. - HUGHES, J. B. BATTERSBY, N. C.: Switched current an analogue technique, Peter Peregrinus Ltd, London, 1993.

[8] DOSTÁL, T.: Theory of electric circuits, BUT Brno, pp. 172-196, 2004.

[9] BIČÁK, J. - LAIPERT, M. - VLČEK, M.: Linear circuits and systems, CTU Publisher, Prague, 2007.

[10] ROBERTS, G. W. - SEDRA, A. S.: All currentmode frequency selective circuits, Electron. Lett., 25 (12), pp.759-761, 1989.

[11] BRTNÍK, B.: Basics of the circuit techniques I, Ben Publisher, Prague, 2014.

[12] BRTNÍK, B. - MATOUŠEK, D.: The Adjoint Transformation Usage for Correction of the Attenuation of the Low-pass Biquad in the Current Mode, In: Radioelektronika 2016, Proceedings of the 26th International Conference, Košice, 2016.

Received May 2, 2016, accepted June 27, 2016

\section{BIOGRAPHIES}

Bohumil Brtník was born on 27.4.1959. In 1983 he graduated (MSc) at the department of Telecommunications of the Faculty of Electrical Engineering and Communication at Technical University in Brno. He defended his PhD in the field electronics, communication and measurement technic in 1998. Currently, he is in University of Pardubice, Faculty of Electrical Engineering and Informatics. His scientific research are electric circuits.

David Matoušek was born on 27.10.1972. In 1996 he graduated (MSc) at the department of Microelectronics of the Faculty of Electrical Engineering at Czech Technical University in Prague. He is working in Department of Electrical Engineering of the Faculty of Electrical Engineering and Informatics of the University of Pardubice. His scientific research are electronic circuits, microcontrollers and digital signal processing. 